Esta revista forma parte del acervo de la Biblioteca Jurídica Virtual del Instituto de Investigaciones Jurídicas de la UNAM http://www.juridicas.unam.mx https://biblio.juridicas.unam.mx

https://revistas.juridicas.unam.mx DOI: http://dx.doi.org/10.22201/iij.24484881e.2021.44.16168

COMENTARIOS

JURISPRUDENCIALES 
Esta revista forma parte del acervo de la Biblioteca Jurídica Virtual del Instituto de Investigaciones Jurídicas de la UNAM

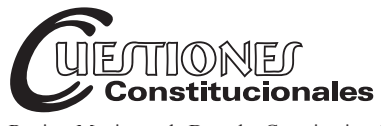

Revista Mexicana de Derecho Constitucional

Núm. 44, Enero-Junio 2021

ISSN (versión electrónica): 2448-4881

\title{
Corpos inquietos, sexualidades "desviantes" e o devir de novas narrativas jurídicas nas Cortes constitucionais
}

\author{
Restless bodies, "deviant" sexualities and the becoming \\ of new legal narratives in constitutional Courts
}

\author{
Doglas CESAR LUCAS* \\ Pâmela COPETTI GHISLENI**
}

RESUMO: As sociedades contemporâneas fizeram da sexualidade, dos afetos e do desejo categorias centrais no que diz respeito à construção da subjetividade do sujeito, de modo que a concretização dos direitos humanos atravessa, invariavelmente, os corpos e as sexualidades. Nesse sentido, este texto intenta fazer apresentar, de forma bem objetiva, uma análise jurisprudencial representativa das mais altas Cortes jurisdicionais, nacionais ou internacionais, e em cujo cerne circulam as questões do gênero e da sexualidade. A escolha dos casos levou em consideração os critérios geográfico-espacial e cronológico, selecionando-se os entendimentos mais relevantes dos tribunais de países ocidentais e ocidentalizados, mas com diferentes realidades culturais, sociais e econômicas, para além de decisões envolvendo
ABSTRACT: Contemporary societies have made sexuality, affections, and desire central categories regarding the construction of the subjectivity of the subject, so that the realization of human rights invariably crosses bodies and sexualities. In this sense, this text intends to present, in a very objective way, a jurisprudential analysis representative of the highest jurisdictional Courts, national or international, and at the heart of which issues of gender and sexuality circulate. The choice of cases considered the geographicspatial and chronological criteria, selecting the most relevant understandings of the courts of western and westernized countries, but with different cultural, social and economic realities, in addition to decisions involving Regional Courts for the protection of human rights. In the end, it is evident that

* Professor universitário e Advogado. UNIJUÍ - Universidade Regional do Noroeste do Estado do Rio Grande do Sul e Faculdade CNEC Santo Ângelo, Brasil. Correo electrónico:doglasl@unijui.edu.br ORCID: 0000-0003-3703-3052.

** Professora universitaria e Advogada. Faculdade CNEC Santo Ângelo, RS, Brasil. Correo electrónico:pcghisleni@gmail.com ORCID:0000-0003-0166-9462. 
Esta revista forma parte del acervo de la Biblioteca Jurídica Virtual del Instituto de Investigaciones Jurídicas de la UNAM

Cortes regionais de proteção de direitos humanos. Ao final, evidencia-se que o Direito, por meio dos tribunais, vem enfrentando, incorporando e narrando esses novos temas, sinalizando para uma importante mudança de paradigma em termos de justiça de gênero e sexualidade.

Palavras-chave: Cortes Constitucionais, diferença, direitos sexuais, gênero, sexualidade. the Law, through the courts, has been facing, incorporating, and narrating these new themes, signaling an important paradigm shift in terms of gender and sexuality justice.

Keywords: Constitutional Courts, difference, sexual rights, gender, sexuality.

SuMÁRIO: I. Considerações iniciais. II. Corpos inquietos, sexualidades "desviantes" e o que dizem os Tribunais. III. Conclusão (ou reflexões para não concluir). IV. Referências.

\section{CONSIDERAÇÕES INICIAIS}

Se no passado as relações interpessoais se estabeleciam a partir de critérios muito convencionais, no mundo contemporâneo a lógica dos afetos e do desejo passou a permear e alicerçar uma imensa gama de relacionamentos. Essas e outras transformações contribuíram para que a sexualidade se tornasse objeto de estudo de diversos campos de saber (médico, psicanalítico, jurídico, econômico, sanitário etc.). Cada disciplina faz um esforço a partir de seus próprios interesses e horizontes epistemológicos para propor (quando não impor) uma definição ou visão dominante a respeito da sexualidade e dos temas que lhe são sensíveis.

Não se pode negar, entretanto, que há um movimento significativo de visibilização de novas identidades e sexualidades que requerem agora um reconhecimento efetivo na cena pública. Isso significa que é possível visualizar, hoje, um importante engajamento que está desconstruindo ou ao menos revisando a literatura que concebeu a sexualidade e o gênero como aspectos previamente dados do ser humano. Por outro lado, é também verdadeiro que à medida em que avança a pauta de conquista de direitos de pessoas LGBTI, ${ }^{1}$ evoluem na mesma proporção (quando não mais inten-

1 Sigla usada para designar as pessoas lésbicas, gays, bissexuais, travestis, transexuais e intersexuais. A utilização da abreviatura, neste texto, tem por objetivo tornar o trabalho mais palatável ao grande público e de fácil comunicação. Entretanto (e este esclarecimento Cuestiones Constitucionales, Núm. 44, Enero-Junio 2021 ISSN: $2448-4881$ 
Esta revista forma parte del acervo de la Biblioteca Jurídica Virtual del Instituto de Investigaciones Jurídicas de la UNAM

samente) as investidas de grupos conservadores que tentam a todo o custo barrar essas novas possibilidades que a vida e os corpos oferecem. Quando essa discussão "bate à porta" do edifício jurídico, de que maneira os tribunais têm respondido juridicamente aos anseios da população LGBTI, já que todo o ordenamento jurídico vinha (e de certo modo ainda vem) calcado em um modelo de inteligibilidade de corpos consubstanciado na lógica binária dos gêneros e na matriz heterossexual da lei?

Nesse sentido, este texto pretende estabelecer alguns parâmetros que evidenciem de que maneira os tribunais vêm enfrentando as novas demandas do gênero e da sexualidade, a fim de compreender se os posicionamentos adotados eventualmente sinalizam para uma mudança de paradigma em nível global.

Para desenvolvimento da pesquisa, foi fundamental a análise de jurisprudências representativas dos temas ora pautados, as quais foram selecionadas levando-se em consideração basicamente os critérios geográfico-espacial e cronológico, abordando-se os entendimentos mais relevantes das mais altas Cortes jurisdicionais, nacionais ou internacionais, de países ocidentais e ocidentalizados, mas com diferentes realidades culturais, sociais e econômicas. Para além disso, o critério cronológico foi fundamental, pois objetivou-se compreender o atual estado da arte no que tange às questões envolvendo gênero e sexualidade nos tribunais contemporâneos, o que justifica a preocupação em fazer menção aos casos tidos como paradigmáticos e/ou mais recentes naqueles órgãos.

\section{CORPOS INQUIETOS, SEXUALIDADES "DESVIANTES" E O QUE DIZEM OS TRIBUNAIS}

Se até pouco tempo atrás expressões como sexo, desejo e sexualidade costumavam circular quase que com exclusividade na academia e na militância, hoje tais termos experimentam um importante processo de legitimação. Importante porque embora realmente não sejam autossuficientes, são os instrumentos normativos que dão sustentabilidade, num primeiro momento, para a efetivação de direitos humanos. Num passado ainda mais recente, os direitos sexuais foram (e estão sendo inseridos) nesse processo lento e gradual de consolidação de uma nova gramática dos direitos humanos, que

é fundamental), não se desconhece o fato de que existem identidades, corporalidades e sexualidades outras que transcendem (e muito) a designação trazida pela sigla. 
Esta revista forma parte del acervo de la Biblioteca Jurídica Virtual del Instituto de Investigaciones Jurídicas de la UNAM

deságua, pouco a pouco, nos tribunais. Nesse sentido, esta última seção visa a compreender de que maneira o Direito, por meio dos tribunais, está enfrentando as demandas da sexualidade em um mundo em constante e veloz transformação, que em movimentos ininterruptos questiona e ressignifica categorias até então sólida e sedentariamente dadas.

Reitera-se aqui, em zelo à metodologia, que os casos escolhidos levaram em consideração basicamente três critérios. O critério óbvio e primário é aquele da seleção dos casos oriundos das altas Cortes jurisdicionais, nacionais ou internacionais, a partir da relevância temática do julgamento e sua afinidade com os temas do gênero e da sexualidade. Além disso, há preocupação com o critério geográfico-espacial, na medida em que foram escolhidos casos originários de países ocidentais e ocidentalizados, bem como de suas Cortes regionais respectivas. Por fim, o aspecto cronológico também foi levado em consideração, já que se objetivou compreender o atual estado da arte no que tange às questões envolvendo gênero e sexualidade nos tribunais, o que justifica a preocupação com os julgamentos tidos como paradigmáticos e/ou mais recentes. Alerta-se, finalmente, para o fato de que os casos são apresentados, neste item, independentemente da ordem cronológica, mas atendendo à coesão do raciocínio aqui traçado.

No Brasil, o Supremo Tribunal Federal (STF) julgou conjuntamente, em maio de 2011, a Ação Declaratória de Constitucionalidade (ADI) 4.277/DF (BRASIL, 2011a) - protocolada inicialmente como Arguição de Descumprimento de Preceito Fundamental (ADPF) no 178 - e a Arguição de Descumprimento de Preceito Fundamental (ADPF) 132/RJ. AADI foi ajuizada pela Procuradoria-Geral da República e a ADPF pelo então Governador do Rio de Janeiro, Sérgio Cabral. Em ambas as demandas, discutia-se o reconhecimento da união estável entre pessoas do mesmo sexo como entidade familiar. É que o parágrafo $3^{\circ}$ do artigo 226 da Constituição Federal preceitua que "para efeito da proteção do Estado, é reconhecida a união estável entre o homem e a mulher como entidade familiar". O Relator das ações, Ministro Ayres Britto, votou no sentido de dar interpretação conforme a Constituição Federal, excluindo do artigo 1.723 do Código Civil (que regula as uniões estáveis) qualquer significado que impeça o reconhecimento da união entre pessoas do mesmo sexo como entidade familiar. No ponto central, o reconhecimento do direito de casais homossexuais foi unânime. ${ }^{2}$

2 É de ser mencionada a constatação do então advogado no caso, Luis Roberto Barroso, atualmente ministro do STF, em sua sustentação oral em defesa da união homoafetiva. O jurista aduziu que a inclusão expressa do termo "mulher" na Constituição Federal de Cuestiones Constitucionales, Núm. 44, Enero-Junio 2021

ISSN: $2448-4881$ 
Esta revista forma parte del acervo de la Biblioteca Jurídica Virtual del Instituto de Investigaciones Jurídicas de la UNAM

Com esse paradigmático julgamento, consolidou-se "uma nova perspectiva da família e da sua função na sociedade, que se volta para a plena realização dos direitos fundamentais, sobretudo a dignidade da pessoa humana". ${ }^{3}$

Mais recentemente, outro grande avanço foi galgado no que diz respeito às uniões estáveis, o que invariavelmente vai repercutir positivamente na vida de casais homossexuais, especialmente do ponto de vista econômico. É que em julgamento de maio de 2017, o STF decidiu pela inconstitucionalidade do artigo 1.790 do Código Civil, que estabelece diferenças entre a participação do companheiro e do cônjuge na sucessão de bens. A decisão, com repercussão geral reconhecida, foi proferida no Recurso Extraordinário (RE) 878.694, que trata de união de casal heteroafetivo, e no Recurso Extraordinário (RE) 646.721, que aborda sucessão em uma relação homoafetiva. Por conseguinte, firmou-se entendimento no sentido de que no sistema constitucional vigente é inconstitucional a diferenciação de regime sucessório entre cônjuges e companheiros, devendo ser aplicado em ambos os casos o regime estabelecido no artigo 1.829 do Código Civil, que regula a sucessão legítima.

Ainda no cenário latino-americano, a Corte Constitucional da Colômbia vem protagonizando um importante processo de legitimação de direitos de minorias sexuais. Em 2011, o país reconheceu a possibilidade de que casais homossexuais constituíssem família. Em 2013, tais casais foram contemplados com igualdade de direitos em relação aos direitos dos vínculos heterossexuais. Em abril de 2016, a Corte deliberou, em votação conjunta de seis expedientes acumulados de tutela, por seis votos a três, favoravelmente ao casamento entre pessoas do mesmo sexo. Por meio da sentença SU-214/16, a Corte concedeu aplicação analógica ao matrimônio civil, constante do artigo 113 do Código Civil Colombiano, garantindo o direito constitucional de formar uma família também a parceiros do mesmo sexo.

1988 deveu-se à necessidade de pôr fim à discriminação de gênero relativamente a mulheres que não possuíam os mesmos direitos patrimoniais no casamento. "Esse dispositivo" - diz Barroso - "está aqui para incluir as mulheres e não para excluir os homossexuais e as relações homoafetiva, das quais o Constituinte não cuidou". In: A DEFESA das uniões homoafetivas perante o STF: uma visão humanista da vida (parte 1). Disponível em: https:// www.youtube.com/watch?v=5_CHQPes_ls. Acesso em: 09 dez. 2017. Essa percepção evidencia aquilo que já foi mencionado na seção anterior, no sentido de que a lógica jurídica inclui invariavelmente excluindo.

3 Roesler, Claudia Rosane; Santos, Paulo Alves. Argumentação jurídica utilizada pelos tribunais brasileiros ao tratar das uniões homoafetivas. Revista Direito GV, São Paulo, v. 10, n. 2, p. 615-638, dez. 2014, p. 636. 
Esta revista forma parte del acervo de la Biblioteca Jurídica Virtual del Instituto de Investigaciones Jurídicas de la UNAM

Outras duas decisões a cargo da Corte Constitucional da Colômbia abordam a temática da sexualidade de modo paradigmático. Na sentença T-629/2010, o Tribunal decidiu dar a homens e mulheres que se prostituem os mesmos direitos estendidos para trabalhadores de qualquer outra profissão, inclusive no que se refere à licença-maternidade. Em 2013, na decisão T-372/2013, o Tribunal da Colômbia ordenou que diretor de um estabelecimento prisional permitisse a visita íntima para pessoas LGBTI, garantindo a privacidade, a não discriminação e o desenvolvimento livre da personalidade, independentemente de orientação sexual. ${ }^{4}$

No México, a Suprema Corte de Justiça da Nação, em julgamento histórico, de 2015, respaldou as uniões homossexuais, equiparando-as plenamente às heterossexuais. É que no cenário mexicano, cada Estado regulamenta o casamento a partir de um Código Civil que lhe é próprio e em muitos casos essas normativas estabelecem que a finalidade do casamento é a procriação, aspecto veementemente negado pela Suprema Corte daquele país. Nesse sentido, os julgadores afirmaram categoricamente que

...considerar que la finalidad del matrimonio es la procreación constituye una medida no idónea para cumplir con la única finalidad constitucional a la que puede obedecer la medida: la protección de la familia como realidad social. Pretender vincular los requisitos del matrimonio a las preferencias sexuales de quienes pueden acceder a la institución matrimonial con la procreación es discriminatorio, pues excluye injustificadamente del acceso al matrimonio a las parejas homosexuales que están situadas en condiciones similares a las parejas heterosexuales.

A liberdade de orientação sexual desaguou também no Tribunal do "sonho americano”. Em junho de 2015, a Suprema Corte dos Estados Unidos,

4 Ainda na República Colombiana, mas desta vez felizmente prescindindo da atuação dos tribunais, outro caso ganhou destaque dadas as suas particularidades. Em junho de 2017, três homens colombianos de Medellín, Manuel, Victor Hugo e Alejandro, constituíram um regime de "trieja" (ou trisal). Nesse caso, com a formalização da escritura pública, o casamento entre os três assume implicações perfeitamente jurídicas, tanto no que se refere à separação ou ao falecimento de qualquer dos cônjuges, quanto no que diz respeito à eventual adoção de uma criança. Quando questionado pelo grupo de reportagem sobre ser possível amar mais de uma pessoa, Manuel limitou-se a afirmar que "lo raro es decir que uno sólo puede amar a una persona.” In: Marín, Daniel Rivera. Los tres maridos: la historia de una "trieja", la unión marital de tres hombres en Colombia. BBC Mundo. 15 jun. 2017. Vale lembrar que o Brasil, em 2016, já havia reconhecido uma união poliafetiva entre duas mulheres e um homem perante o $15^{\circ}$ Ofício de Notas do Rio de Janeiro.

Cuestiones Constitucionales, Núm. 44, Enero-Junio 2021

ISSN: $2448-4881$ 
Esta revista forma parte del acervo de la Biblioteca Jurídica Virtual del Instituto de Investigaciones Jurídicas de la UNAM

em uma decisão histórica, legalizou, por cinco votos a quatro, a união entre pessoas do mesmo sexo. Desde então, todas as áreas sujeitas à jurisdição da Constituição dos Estados Unidos não podem opor resistência injustificada ao reconhecimento do casamento homossexual. O caso Obergefell e Outros vs. Hodges trata da relação homossexual entre Obergefell e John Arthur, companheiros por mais de vinte anos. Em 2011, Arthur foi diagnosticado com esclerose lateral amiotrófica, motivo pelo qual o casal formalizou a união em Maryland, em outubro de 2013. No entanto, quando se mudaram para Ohio e postularam o reconhecimento da licença de casamento junto às autoridades, o Estado negou referida licença, de modo que o casal ajuizou uma ação em face do governador do distrito de Ohio. Em 2014, o Tribunal de Apelações do $6^{\circ}$ Circuito decidiu, por dois votos a um, que a proibição de casamento entre homossexuais não violava a Constituição. Na Suprema Corte, entretanto, a decisão que prevaleceu foi aquela segundo a qual o casamento entre homossexuais não poderia ser proibido, tendo sido determinado seu reconhecimento e validade em toda a jurisdição americana.

O mesmo ideal guiou a decisão da Corte Interamericana de Direitos Humanos (Corte IDH) no caso Atala Riffo e Filhas vs. Chile, de 2012. Nele, o Estado chileno restou condenado por violação dos direitos de igualdade, de respeito à honra e à dignidade, do direito de não discriminação, da vida privada e da garantia judicial de imparcialidade relativamente à Sra. Karen Atala Riffo. A discussão diz respeito à lesbianidade da vítima, a qual perdeu a guarda de suas três filhas para seu ex-companheiro em decisão da Suprema Corte Chilena, cujos motivos mencionaram expressamente a sua orientação sexual. Ainda sob a jurisdição da Corte IDH, a República da Colômbia foi condenada no caso Ángel Alberto Duque vs. Colômbia pela falta de acesso do Sr. Alberto Duque à pensão por morte de seu companheiro falecido em 15 de setembro de 2001. É que as normas que à época regulavam o direito de seguridade social no país excluíam as uniões estabelecidas entre pessoas do mesmo sexo. Em 26 de fevereiro de 2016, a Corte IDH prolatou sentença por meio da qual declarou a responsabilidade internacional da Colômbia pela violação do direito de igualdade perante a lei e de não discriminação em prejuízo do Sr. Duque.

No cenário europeu, merece destaque o Reino da Dinamarca por ter sido o primeiro país do mundo a permitir, ainda em 1989, a união civil entre pessoas do mesmo sexo. Foi um dos pioneiros, também, na autorização do casamento de homossexuais, em 2012. Agora o debate volta à cena pública 
Esta revista forma parte del acervo de la Biblioteca Jurídica Virtual del Instituto de Investigaciones Jurídicas de la UNAM

por meio do caso $\mathrm{n}^{\circ} 159 / 2016$, em que se discutiu se as regras do casamento entre pessoas do mesmo sexo seriam contrárias à Constituição dinamarquesa, essencialmente no que dizia respeito à autoridade dos sacerdotes na Igreja da Dinamarca para casá-las. A Suprema Corte do país, entretanto, concluiu que não havia fundamentos para afastar a autoridade do Poder Legislativo e a deliberação do governo em torno da possibilidade de que duas pessoas do mesmo sexo se casassem na Igreja Dinamarquesa em cerimônia presidida por um sacerdote. Isso porque a base confessionária do país é a Evangélica Luterana e a autoridade máxima para regulamentar as questões da própria Igreja reside no Poder Legislativo e no governo, os quais têm ampla margem de atuação no tocante à regulamentação da possibilidade dos casamentos entre pessoas do mesmo sexo. Por fim, o Tribunal asseverou que inexistem legislações destinadas a limitar o Poder Legislativo e o governo no que tange aos assuntos da Igreja da Dinamarca. Ademais, afirmou que essa interferência não violava a Constituição e nem a Convenção Europeia de Direitos Humanos sobre Liberdade de Crença e Religião.

O caso Carvalho Pinto de Sousa Morais vs. Portugal, do Tribunal Europeu de Direitos Humanos (TEDH), evidencia que o desejo heterossexual também não passa ileso pelo crivo dos conservadores que tentam (e é sempre uma tentativa, não raras vezes fracassada) "normalizar" comportamentos. A vítima da demanda foi submetida a procedimento cirúrgico em virtude do qual sofreu danos permanentes em sua vida íntima e sexual. O Supremo Tribunal Administrativo reduziu o valor de indenização anteriormente arbitrada por entender que, em função de a vítima já contar com 50 anos de idade e ser mãe de dois filhos, o sexo não assumiria a mesma relevância de quando se é mais jovem. Os julgadores do Tribunal Europeu entenderam que houve uma injustificada diferença de tratamento da vítima com base em dois estereótipos bem marcados: gênero e idade. A decisão do TEDH, de julho de 2017, foi no sentido de reconhecer que Portugal violou o direito de não discriminação constante da Convenção Europeia de Direitos Humanos, arbitrando indenização pelos danos morais resultantes dessa violação.

Superadas algumas pautas, no entanto, outras persistem para aquelas sexualidades outrora (e ainda) enquadradas como "desviantes". A doação de sangue por homossexuais é oficialmente proibida pela Anvisa (Resolução RDC nº 34/14) e pelo Ministério da Saúde (Portaria no 158/16).

Ambas as instituições determinam que homens que mantiverem relações sexuais com outros homens nos últimos 12 meses não podem doar sangue.

Cuestiones Constitucionales, Núm. 44, Enero-Junio 2021

ISSN: 2448-4881 
Esta revista forma parte del acervo de la Biblioteca Jurídica Virtual del Instituto de Investigaciones Jurídicas de la UNAM

A Resolução RDC n ${ }^{0}$ 34/14 da Anvisa, em seu art. 25, inciso XXX, estabelece que os contatos sexuais que envolvam riscos de contrair infecções transmissíveis pelo sangue devem ser avaliados e os candidatos nestas condições devem ser considerados inaptos temporariamente por um período de 12 meses após a prática sexual de risco, incluindo-se indivíduos do sexo masculino que tiveram relações sexuais com outros indivíduos do mesmo sexo e/ou as parceiras sexuais destes. Já a Portaria $n^{\circ} 158$ do Ministério da Saúde, de 04 de fevereiro de 2016, em seu art. 64, considera inaptos temporários por 12 meses os candidatos homens que tiverem relações sexuais com outros homens e/ou as parceiras sexuais destes. Há vários anos, especialistas de saúde não somente no Brasil, mas no mundo todo, advogam pelo fim da proibição imposta aos homossexuais, por considerarem a medida improcedente, preconceituosa e desarrazoada, sendo um incoerente resquício da epidemia do vírus HIV no país. Argumentam tais especialistas que o conceito de "grupo de risco" já não se aplica. O que deve ser levado em consideração nessas proibições sanitárias é o comportamento de risco.

Nesse sentido, em maio de 2020, o Plenário do STF, por maioria de votos (7x4), considerou inconstitucionais os dispositivos mencionados. Prevaleceu o voto do Ministro Relator, Edson Fachin, no sentido de julgar procedente a ADI $\mathrm{n}^{\circ}$ 5.543, ajuizada pelo Partido Socialista Brasileiro (PSB). Como bem asseverou o Ministro Relator,

...sangue e pertencimento têm, ao longo da história, penduleadoentre os extremos do acolhimento e da exclusão... Para além dessa dimensão individual, no campo simbólico o sangue corresponde à negativa de qualquer possibilidade de arrebatamento da humanidade de quem quer que seja por motivos como "raça", cor, gênero, orientação sexual, língua, religião, origem etc. O sangue como metáfora perfeita do que nos faz inerentemente humanos... A responsabilidade com o Outro no caso em tela nos convida, portanto, a realizar uma desconstrução do Direito posto para tornar a Justiça possível. Incutir, na interpretação do Direito, o compromisso com um tratamento igual e digno a essas pessoas que desejam exercer a alteridade e doar sangue. Somos responsáveis pela resposta que apresentamos a esse apelo. (Brasil, 2020).

No que diz respeito à questão de gênero, de grande relevância têm sido as decisões não somente oriundas de casos contenciosos, mas também da atuação consultiva da Corte Interamericana. Em seu último parecer consultivo (OC $\left.n^{\circ} 24 / 17\right)$, solicitado pela Costa Rica, a Corte esclareceu a obrigação de o Estado reconhecer e facilitar a mudança de nome das pessoas de 
Esta revista forma parte del acervo de la Biblioteca Jurídica Virtual del Instituto de Investigaciones Jurídicas de la UNAM

acordo com a identidade de gênero de cada uma (inclusive no que se refere aos menores de 18 anos). Nele, a Corte observa que os procedimentos de natureza administrativa ou notarial (em detrimento do jurisdicional) são aqueles que melhor atendem à demanda de pessoas trans., de modo que: a) devem estar focados na adequação integral da identidade de gênero autopercebida; b) devem estar baseados unicamente no consentimento livre e informado do solicitante sem que exijam requisitos como certificações médicas e/ou psicológicas ou outros que possam resultar não razoáveis e patologizantes; c) devem ser confidenciais; d) devem ser rápidos e, na medida do possível, gratuitos; e e) não devem exigir a realização de operações cirúrgicas e/ou hormonais. A Corte estimou também que devem ser protegidos, sem discriminação alguma com respeito aos casais de pessoas heterossexuais, em conformidade com o direito à igualdade e à não discriminação (artigos 1.1 e 24), todos os direitos patrimoniais que derivam do vínculo familiar protegido entre pessoas do mesmo sexo. ${ }^{5}$ Isso significa que os Estados devem respeitar e garantir a toda pessoa a possibilidade de registrar e inclusive mudar, retificar ou adequar o seu nome e os demais componentes essenciais de sua identidade, a exemplo da imagem, da referência ao sexo ou gênero, independentemente de quaisquer interferências por parte de autoridades públicas ou terceiros. Por isso, as pessoas que se identificam com identidades de gênero diversas devem ser reconhecidas do modo como queiram, o que significa que o Estado deve garantir a tais grupos o exercício desse direito tão elementar. Portanto, em resposta à primeira

5 A Corte assentou ainda que “...la evolución del matrimonio da cuenta de que su actual configuración responde a la existencia de complejas interacciones entre aspectos de carácter cultural, religioso, sociológico, económico, ideológico y lingüístico. En ese sentido, la Corte observa que en ocasiones, la oposición al matrimonio de personas del mismo sexo está basada en convicciones religiosas o filosóficas. El Tribunal reconoce el importante rol que juegan dichas convicciones en la vida y en la dignidad de las personas que la profesan; no obstante, éstas no pueden ser utilizadas como parámetro de convencionalidad puesto que la Corte estaría impedida de utilizarlos como una guía interpretativa para determinar los derechos de seres humanos. En tal sentido, el Tribunal es de la opinión que tales convicciones no pueden condicionar lo que la Convención establece respecto de la discriminación basada en orientación sexual. Es así como en sociedades democráticas debe existir coexistencia mutuamente pacífica entre lo secular y lo religioso; por lo que el rol de los Estados y de esta Corte, es reconocer la esfera en la cual cada uno de éstos habita, y en ningún caso forzar uno en la esfera de otro". In: Corte Interamericana de Direitos Humanos (Corte IDH). Opinião Consultiva n ${ }^{\circ}$ 24/17 (OC n ${ }^{\circ}$ 24/17). 24 nov. 2017b. Disponível em: http://www.corteidh.or.cr/docs/opiniones/seriea_24_esp.pdf. Acesso em: 28 set. 2019 , p. 85.

Cuestiones Constitucionales, Núm. 44, Enero-Junio 2021

ISSN: $2448-4881$ 
Esta revista forma parte del acervo de la Biblioteca Jurídica Virtual del Instituto de Investigaciones Jurídicas de la UNAM

pergunta formulada pela Costa Rica, a Corte concluiu que a mudança de nome, a adequação da imagem e a retificação do sexo ou gênero nos registros e nos documentos de identificação, a fim de que fiquem conformes à identidade de gênero autopercebida pelo sujeito, é um direito protegido pelo artigo 18 da Convenção (direito ao nome) e também pelos artigos 3 (reconhecimento da personalidade jurídica), 7.1 (liberdade) e 11.2 (direito à vida privada), todos da Convenção Americana de Direitos Humanos.

Nesse passo, o Brasil, por meio do Supremo Tribunal Federal, em boa medida influenciado pela Corte Interamericana, tem tomado decisões (contramajoritárias) importantes de defesa dos direitos de pessoas transexuais e transgêneras, uma das quais protagonizada nos autos da Ação Declaratória de Inconstitucionalidade (ADI) 4275/DF, ajuizada perante o STF pela Procuradoria-Geral da República (PGR) em 21/07/2009, em face da redação do artigo 58 da Lei de Registros Públicos (Lei n ${ }^{0}$ 6.015/1973). O julgamento da ação, realizado em março de 2018, que ao final foi tida como procedente por maioria de votos para o fim de dar interpretação conforme a Constituição e o Pacto de São José da Costa Rica ao dispositivo legal em questão, restou assim ementado:

AÇÃO DIRETA DE INCONSTITUCIONALIDADE. DIREITO CONSTITUCIONAL E REGistral. PESSOA TRANSGÊNERO. AlteraÇÃo DO PRENOME E DO SEXO NO REGISTRO CIVIL. POSSIBILIDADE. DIREITO AO NOME, AO RECONHECIMENTO DA PERSONALIDADE JURÍDICA, À LIBERDADE PESSOAL, À HONRA E À DIGNIDADE. INEXIGIBILIDADE DE CIRURGIA DE TRANSGENITALIZAÇÃO OU DA REALIZAÇÃO DE TRATAMENTOS HORMONAIS OU PATOLOGIZANTES. 1. O direito à igualdade sem discriminações abrange a identidade ou expressão de gênero. 2. A identidade de gênero é manifestação da própria personalidade da pessoa humana e, como tal, cabe ao Estado apenas o papel de reconhecê-la, nunca de constituí-la. 3. A pessoa transgênero que comprove sua identidade de gênero dissonante daquela que lhe foi designada ao nascer por autoidentificação firmada em declaração escrita desta sua vontade dispõe do direito fundamental subjetivo à alteração do prenome e da classificação de gênero no registro civil pela via administrativa ou judicial, independentemente de procedimento cirúrgico e laudos de terceiros, por se tratar de tema relativo ao direito fundamental ao livre desenvolvimento da personalidade. 4. Ação direta julgada procedente. (ADI 4275, Relator: Min. Marco Aurélio, Relator p/ Acórdão: Min. Edson Fachin, Tribunal Pleno, julgado em 01/03/2018, Publicado em 07/03/2019). 
Esta revista forma parte del acervo de la Biblioteca Jurídica Virtual del Instituto de Investigaciones Jurídicas de la UNAM

Ao final, o julgamento da ADI foi no sentido de que o transgênero tem direito fundamental subjetivo à alteração de seu prenome e de sua classificação de gênero no registro civil, não se exigindo, para tanto, nada além da manifestação de vontade do indivíduo, faculdade que pode ser exercida tanto pela via judicial, como pela administrativa. Essa alteração, é bom dizer, será averbada à margem do assento de nascimento, vedando-se expressamente a inclusão do termo "transgênero". ${ }^{6}$ Em outras palavras, a pessoa transgênera que comprove sua identidade de gênero dissonante daquela que lhe foi designada no nascimento, fazendo-o por autoidentificação firmada em declaração escrita, tem direito subjetivo à alteração do prenome e da classificação de gênero no registro civil, seja administrativa ou judicialmente e, é bom dizer, independentemente de quaisquer procedimentos cirúrgicos, tratamentos e laudos de terceiros.

A breve descrição dos casos selecionados permite perceber que há um movimento interessante, em nível global, tendente ao reconhecimento jurídico de outras possibilidades familiares e existenciais. Por certo, as últimas décadas demarcaram um período em que restou evidente a discrepância entre a experiência social das pessoas LGBTI e suas expectativas em termos de reconhecimento jurídico. Com isso, o Direito percebe-se constantemente desafiado, no sentido de reinventar sua função reguladora e emancipatória, cujas bases se fizeram sob o paradigma da Modernidade. ${ }^{?}$

Desnecessário dizer que esse processo de reconhecimento e de luta pelos direitos de pessoas LGBTI tem, em maior ou menor grau, sido protagonizado sobretudo pelo Poder Judiciário, seja nacional ou internacional. O Poder Legislativo tem tido uma atuação mais lenta, especialmente nos temas que impõem fortes rupturas paradigmáticas, a exemplo da demanda afetivo-sexual de pessoas LGBTI. Em boa medida, isso deriva do fato de

6 A esse respeito, são interessantes os apontamentos do Ministro Luiz Fux, para quem, “em termos vulgares, não existe um 'orgulho trans'. O sujeito transexual não se identifica como pertencente ao grupo dos transgêneros ou a um terceiro grupo, mas vê-se como homem ou mulher, à semelhança de outros homens e mulheres. Por essa razão, pretende a universalização de direitos e sua inclusão social, como os demais indivíduos." In: Brasil. Supremo Tribunal Federal. Ação Declaratória de Inconstitucionalidade n ${ }^{\circ}$ 4.275/DF, julgada em 8 fev. e 1 mar. 2018. Requerente: Procuradoria-Geral da República. Relator: Ministro Marco Aurélio. Redator do Acórdão: Ministro Edson Fachin. Brasília, 01 mar. 2019, p. 94.

7 Santos, André Leonardo Copetti; Lucas, Doglas Cesar. A (in)diferença no direito. Porto Alegre: Livraria do Advogado, 2015.

Cuestiones Constitucionales, Núm. 44, Enero-Junio 2021

ISSN: $2448-4881$ 
Esta revista forma parte del acervo de la Biblioteca Jurídica Virtual del Instituto de Investigaciones Jurídicas de la UNAM

que a composição dos parlamentos tende a materializar o senso comum, o que significa a reprodução de uma postura mais conservadora. ${ }^{8}$

$\mathrm{O}$ fato é que decisões judiciais dessa natureza, que desafiam estruturas milenares a partir das quais a sociedade humana se consolidou, certamente significam um grande avanço para o Direito, impondo-lhe constantes remodelações que consigam concordar com as novas dinâmicas sociais. Por outro lado, não se pode negar que surgem novas angústias e complexidades que impõem uma reflexão em torno daquilo que Roudinesco ${ }^{9}$ vai caracterizar como um "terror da abolição da diferença dos sexos, com a perspectiva de uma dissolução da família no fim do caminho." Para a psicanalista, entretanto, apesar do grande número de divórcios, separações e rearranjos conjugais, é inegável que a família segue sendo a mais sólida das instituições humanas.

Essas desconstruções e reelaborações devem servir, no entanto, à ressignificação do lugar do sujeito no mundo. Isso quer dizer que esse interessante movimento de desestabilização de algumas categorias modernas deve recolocar o indivíduo em algum lugar, e não o deixar à deriva, desprovido de locus, acobertando-o sob o ilusório manto da abstração. Eis a importância da diferenciação: criar lugares de não segregação, de não impedimento, construindo e viabilizando novas possibilidades. Esse "fazer jurídico" é fundamental, pois permite que sejam abraçadas pelo universo normativo outras estéticas existenciais possíveis. Além disso, sugere que indivíduos possam colocar o seu afeto no seu objeto de desejo efetivo e, mais do que isso, vivenciar essa forma de desejar livre de qualquer opressão.

Há, portanto, um movimento ambivalente: em termos jurídicos, a identidade - seja ela no que diz respeito à sexualidade, cor, gênero ou idade - não pode se constituir em um obstáculo à concretização de direitos fundamentais e, nesse sentido, é possível questionar a desnecessidade de demarcar estes rasgos de identificação dos sujeitos no campo normativo (já que a inclusão de determinadas categorias, por meio do reconhecimento legal, significa a exclusão de outras). Por outro lado, no que diz respeito ao mundo da vida, dos fatos, esses traços são fundamentais porque comunicam ex-

8 Não se desconhece a realidade de países como a Alemanha, que em junho de 2017 legalizou o casamento entre pessoas do mesmo sexo por meio de projeto de lei aprovado por 393 deputados, integrantes de três partidos de esquerda e de alguns parlamentares da ala conservadora de Angela Merkel.

9 Roudinesco, Elizabeth. A família em desordem. Rio de Janeiro: Jorge Zahar, 2003, p. 11. 
Esta revista forma parte del acervo de la Biblioteca Jurídica Virtual del Instituto de Investigaciones Jurídicas de la UNAM

pectativas e (im)possibilidades para os indivíduos. Desse modo, é possível supor, por exemplo, que uma mulher lésbica queira se identificar como tal em termos existenciais a fim de evitar as investidas arbitrárias de homens que, muito provavelmente, não são seu objeto de desejo.

Não se pode, no entanto, dar a pauta por superada. Em muitas regiões, as pessoas LGBTI ainda não adentraram na arena dos sujeitos socialmente reconhecidos do ponto de vista de sua cidadania. "Manter relacionamentos amorosos, algo que nos faz intrinsecamente humanos, ainda é, em termos legais, uma prerrogativa heterocêntrica, marca da injustiça erótica e da opressão sexual que atinge gays e lésbicas no Brasil e na maior parte do planeta". ${ }^{10}$ Exemplo disso é o fato de que não chega a 30 o número de países que aprovam o casamento entre pessoas do mesmo sexo. ${ }^{11}$

Por outro lado, não há como negar que os desafios introduzidos pela diferença (e pela diferenciação) estão latentes e se colocam cada vez mais na ordem do dia, demandando um reconhecimento político cujas consequências se espraiam para outros campos, a exemplo do econômico. Isso significa que, superadas algumas pautas da agenda LGBTI, outras surgirão, reivindicando novas respostas, mais criativas, capazes de incluir tais grupos outrora excluídos da vida pública numa noção de sexualidade efetivamente cidadã, a fim de que os direitos sexuais sejam eles também percebidos como parte do exercício da cidadania.

\section{CONCLUSÃo (OU REFLEXÕES PARA NÃO CONCLUIR)}

A construção e consolidação do ambiente democrático não somente tolera como fomenta a diversidade. No entanto, pari passu com as possibilidades democráticas, vislumbra-se aquilo que podemos chamar de uma ditadura da identidade, a qual faz com se perca o que há de mais essencial em nossa subjetividade quando somos obrigados a narrar, nas entrelinhas, quem somos. Essa gramática castradora faz com que nos esqueçamos do fato de que "nossa identidade é tragada pela diferença", ${ }^{12}$ de modo que existir

\footnotetext{
10 Mello, Luiz. Familismo (anti)homossexual e regulação da cidadania no Brasil. Estudos Feministas, Florianópolis, v. 14, n. 2, p. 497-508, jan. 2006, p. 506.

11 ILGA. Sexual orientation laws in the world-Overview. Maio 2017. Disponível em: http://ilga.org/downloads/2017/ILGA_WorldMap_ENGLISH_Overview_2017.pdf. Acesso em: 28 jan. 2018.

12 Schöpke, Regina. Por uma filosofia da diferença: Gilles Deleuze, o pensador nômade. Rio de Janeiro: Contraponto, 2012, p. 192.
}

Cuestiones Constitucionales, Núm. 44, Enero-Junio 2021

ISSN: $2448-4881$ 
Esta revista forma parte del acervo de la Biblioteca Jurídica Virtual del Instituto de Investigaciones Jurídicas de la UNAM

basta para estar na condição de diferente, de outro. É exatamente por isso que Nietzsche alertou-nos de que todo homem está no mundo apenas uma vez, a título de unicum, e que nenhum acaso, mesmo o mais estranho, combinará por uma segunda vez uma multiplicidade tão bizarra. E não bastasse isso, se o sujeito é sempre e invariavelmente uma diferença em relação aos demais, esse mesmo sujeito é um outro também em relação a si próprio. É por isso que Foucault costumava dizer "eu não sou, eu estou” e bradava contra aqueles que o questionavam sobre sua identidade (filósofo? Historiador das ideias? Teórico social? Filólogo? Crítico literário?) respondendo enfaticamente: "não me pergunte quem sou e não me diga para permanecer o mesmo: é uma moral de estado civil; ela rege nossos papéis. Que ela nos deixe livres quando se trata de escrever". ${ }^{13}$

Com efeito, apesar dos inúmeros avanços encabeçados pelos movimentos feminista, gay, lésbico, trans e de profissionais do sexo, ainda há um longo caminho a ser percorrido para que a inserção de tais grupos na vida social efetivamente se verifique do ponto de vista da cidadania e instrumentos legais e políticas públicas a eles relativos surjam de forma abrangente em domínios importantes e efetivos nos Estados. Enquanto isso, o Poder Judiciário, seja no âmbito local, seja no internacional, vem se mostrando como um grande aliado desses grupos quando da tomada de decisões que são fundamentais à concretização dos direitos mais elementares de determinadas identidades vulnerabilizadas.

Nesse sentido, não se pode negar que o modelo familiar heteronormativo persiste como regra no imaginário coletivo, mas a dinâmica social aponta para novas possibilidades que abarcam desde os relacionamentos homossexuais até as uniões poliafetivas. Sexo, gênero e sexualidade, nesse cenário, revelam-se como categorias maleáveis (pela cultura, pela religião, pela biologia) e fluídas, permeadas ora por conservadorismos, ora por ondas liberais. No que se refere às uniões homoafetivas, verifica-se um primeiro processo de descriminalização, passando pela legalização da união civil com posterior equiparação ao casamento heterossexual. Desnecessário dizer que a reivindicação política avançará, exigindo das ciências jurídicas um novo modo de pensar a partir de outras experiências sociais que se colocarão na ordem do dia.

13 Foucault, Michel. A arqueologia do saber. Tradução de Luiz Felipe Baeta Neves. Rio de Janeiro: Forense Universitária, 2008. 
Esta revista forma parte del acervo de la Biblioteca Jurídica Virtual del Instituto de Investigaciones Jurídicas de la UNAM

Os casos analisados abarcaram, dentre outros países, Brasil, Portugal, Estados Unidos, Dinamarca, Colômbia e México, mas guardam em comum o fato de que foram resolvidos pelas mais altas cortes jurisdicionais. Embora materializem um pequeno recorte diante da multiplicidade de outras regiões que poderiam ser estudadas, eles permitem sugerir que está ocorrendo um deslocamento importante a nível global no que diz respeito ao gênero e à sexualidade, no sentido de um reconhecimento cada vez mais enfático da diversidade. Além disso, evidenciam que embora as identidades assumam especial relevância do ponto de vista do cotidiano, talvez seja mais interessante para o Direito (e possivelmente menos problemático) estabelecer direitos fundamentais de maneira desvinculada das identidades e dos marcos regulatórios que se revelam, invariavelmente, excludentes.

É que como um instituto que se estabelece a partir das relações com o seu oposto, incluir - na lógica jurídica - a partir da identificação, inevitavelmente acarretará exclusões. É dizer, toda legislação que se propor a reconhecer explicitamente determinadas identidades está, em verdade, fadada ao fracasso, já que apenas está protegendo processos de identificação. É o caso das uniões homoafetivas, pois na tentativa de proteger a mulher enquanto um sujeito vulnerável em termos de gênero, por melhor que fosse a intenção do legislador constituinte, outras inúmeras identidades tão vulneráveis quanto a própria mulher se percebera sem proteção jurídica adequada.

Então, até que ponto o sistema jurídico consegue universalizar o direito à identidade, especialmente no tocante à sexualidade? Este estudo defende que o Direito, por adotar determinadas generalizações, seleciona certos traços de identificação, afastando outros (igualmente importantes). Talvez seja hora de restaurar, pelo menos do ponto de vista legislativo, uma humanidade comum do ser humano enquanto modelo universal de direitos humanos, o que não implica, necessariamente, adotar uma racionalidade jurídica estandartizadora e sectária. Somente assim será possível conceber um paradigma jurídico de justiça erótica, de libertação sexual e diversidade familiar, reconhecendo que negar os direitos conjugais, parentais e sobretudo existenciais de pessoas LGBTI é a negação expressa de sua própria condição de seres humanos. 
Esta revista forma parte del acervo de la Biblioteca Jurídica Virtual del Instituto de Investigaciones Jurídicas de la UNAM

\section{REFERÊNCIAS}

Brasil. Supremo Tribunal Federal. (2011). Ação de Descumprimento de Preceito Fundamental $n^{\circ}$ 132/RJ. Relator: Min. Ayres Brito, Brasilia. Disponível em: http://redir.stf.jus.br/paginadorpub/paginador.jsp?docTP= $A C \&$ docID $=628633$. Acesso em: 10 dez. 2017.

Brasil. Supremo Tribunal Federal. (2018). Ação Declaratória de Inconstitucionalidade $n^{\circ} 4.275 / \mathrm{DF}$, julgada em 8 fev. e 1 mar. 2018. Requerente: Procuradoria-Geral da República. Relator: Ministro Marco Aurélio. Redator do Acórdão: Ministro Edson Fachin. Disponível em: http://por tal.stf.jus.br/processos/downloadPeca.asp? $i d=15339649246 \&$ ext $=. p d f$. Acesso em: 28 set. 2019.

Brasil. Supremo Tribunal Federal. (2011). Ação Direta de Inconstitucionalidade $n^{\circ}$ 4.277/DF. Relator: Min. Ayres Britto, Brasília. Disponível em: http://redir.stf.jus.br/paginadorpub/paginador.jsp?docTP $=A C \& d o$ $c I D=628635$. Acesso em: $10 \mathrm{dez} .2017$.

Brasil. Supremo Tribunal Federal. (2016). Medida Cautelar na Ação Direta de Inconstitucionalidade $n^{\circ}$ 5.543/DF. Relator: Min. Edson Fachin, Brasília. Disponível em: http://www.stf.jus.br/portal/processo/verProcesso Peca.asp? $i d=309695587$ \&ipoApp =.pdf. Acesso em: 10 dez. 2017.

Brasil. Supremo Tribunal Federal. (2017). Recurso Extraordinário $n^{\circ} 646$. 721/RS. Relator: Min. Roberto Barroso, Brasília. Disponível em: http:// www.stf.jus.br/portal/processo/verProcessoAndamento.asp? incidente= 4100069. Acesso em: 10 dez. 2017.

Brasil. Supremo Tribunal Federal. (2017). Recurso Extraordinário $n^{\circ} 878$. 694/MG. Relator: Min. Roberto Barroso, Brasília. Disponível em: http:// stf.jus.br/portal/processo/verProcessoAndamento.asp? incidente $=47$ 44004. Acesso em: 10 dez. 2017.

Corte Constitucional de Colombia (CCC). (2016). Comunicado $n^{\circ} 17,28$ abr. 2016. Celebración de matrimonio civil entre parejas del mismo sexo en Colombia. Sentencia de unificación. Disponível em: http://www.cor teconstitucional.gov.co/comunicados/No.\%2017\%20comunicado\%20 28\%20de\%20abril\%20de\%202016.pdf. Acesso em: 09 dez. 2017.

Corte Constitucional de Colombia (CCC). (2013). Decision T-372/13, 2013. Right to conjugal visits for LGBTI people. Disponível em: http://english. 
Esta revista forma parte del acervo de la Biblioteca Jurídica Virtual del Instituto de Investigaciones Jurídicas de la UNAM

corteconstitucional.gov.co/sentences/T-372-2013.pdf. Acesso em: 09 dez. 2017.

Corte Constitucional de Colombia (CCC). (2010). Decision T-629/10, 2010. Protection to the sex workers (prostitution). Disponível em: http://www. corteconstitucional.gov.co/RELATORIA/2010/T-629-10.htm. Acesso em: 09 dez. 2017.

Corte Interamericana de Direitos Humanos (Corte IDH). (2017). Opinião Consultiva $n^{\circ}$ 24/17 (OC n ${ }^{\circ}$ 24/17). Disponível em: http://www.corteidh. or.cr/docs/opiniones/seriea_24_esp.pdf. Acesso em: 28 set. 2019.

Corte Interamericana de Direitos Humanos (Corte IDH). (2012). Sentença. Atala Riffo e Filhas vs. Chile. Disponível em: http://corteidh.or.cr/ docs/casos/articulos/seriec_239_esp.pdf. Acesso em: 14 out. 2017.

Corte Interamericana de Direitos Humanos (Corte IDH). (2016). Sentença. Ángel Alberto Duque vs. Colômbia. Disponível em: http://www.corteidh. or.cr/docs/casos/articulos/seriec_310_esp.pdf. Acesso em: 02 out. 2017. FouCAult, Michel. (2008). A arqueologia do saber. Tradução de Luiz Felipe Baeta Neves. Rio de Janeiro: Forense Universitária.

ILGA. (2017). Sexual orientation laws in the world - Overview. Disponível em: http://ilga.org/downloads/2017/ILGA_WorldMap_ENGLISH_ Overview_2017.pdf. Acesso em: 28 jan. 2018.

MARÍn, Daniel Rivera. (2017). Los tres maridos: la historia de una "trieja", la unión marital de tres hombres en Colombia. BBC Mundo. Disponível em: http://www.bbc.com/mundo/noticias-40286113. Acesso em: 30 out. 2017.

MELlo, Luiz. (2006). Familismo (anti)homossexual e regulação da cidadania no Brasil. Estudos Feministas, Florianópolis, v. 14, n. 2, jan. 2006. Disponível em: https://periodicos.ufsc.br/index.php/ref/article/view/S01 04-026X2006000200010/7761. Acesso em: 28 jan. 2018.

Suprema Corte de Justiça da Nação. (2015). Tesis Jurisprudencial 3/2015. Disponível em: https://suprema-corte.vlex.com.mx/vid/jurisprudencia583152258. Acesso em: 02 dez. 2019.

NietzsChe, Friedrich. (2012). A gaia ciência. Tradução de Paulo César de Souza. São Paulo: Companhia das Letras.

Roesler, Claudia Rosane \& SANTOS, Paulo Alves. (2014). Argumentação jurídica utilizada pelos tribunais brasileiros ao tratar das uniões homoafe- 
Esta revista forma parte del acervo de la Biblioteca Jurídica Virtual del Instituto de Investigaciones Jurídicas de la UNAM

tivas. Revista Direito GV, São Paulo, v. 10, n. 2. Disponível em: http:// www.scielo.br/scielo.php? script $=$ sci_arttext\&pid $=S 1808-2432201400$ $0200615 \& \operatorname{lng}=e n \& n r m=i s o$. Acesso em: 29 out. 2017.

RoudinESCO, Elizabeth. (2003). A família em desordem. Rio de Janeiro: Jorge Zahar.

SANTOS, André Leonardo Copetti \& LuCAS, Doglas Cesar. (2015). A (in) diferença no direito. Porto Alegre: Livraria do Advogado.

SCHÖPKE, Regina. (2012). Por uma filosofia da diferença: Gilles Deleuze, o pensador nômade. Rio de Janeiro: Contraponto.

Suprema Corte da Dinamarca (SCD). (2017). Caso $n^{\circ}$ 159/2016. Same-sex marriage. Disponível em: http://www.supremecourt.dk/supremecourt/nyhe der/Afgorelser/Pages/Same-sexmarriage.aspx. Acesso em: 10 dez. 2017.

Suprema Corte dos Estados Unidos (SCEU). (2015). Case Obergefell vs. Hodges, 26 jun. 2015. Disponível em: https://www.supremecourt.gov/ opinions/14pdf/14-556_3204.pdf. Acesso em: 09 dez. 2017.

Tribunal Europeu de Direitos Humanos (TEDH). (2017). Sentença, Petição $n^{\circ}$ 17484/15. Carvalho Pinto de Sousa Morais vs. Portugal. Disponível em: http://hudoc.echr.coe.int/eng? $i=001-175659$. Acesso em: 31 jul. 2017. 